This is a peer-reviewed, accepted author manuscript of the following article: Javadi, Y., Afzali, O., Raeisi, M. H., \& Najafabadi, M. A. (2013). Nondestructive evaluation of welding residual stresses in dissimilar welded pipes. Journal of Nondestructive Evaluation, 32(2), 177-187. https://doi.org/10.1007/s10921-013-0171-2

\title{
Nondestructive Evaluation of Welding Residual Stresses in Dissimilar Welded Pipes
}

\author{
Yashar Javadi \\ Department of Mechanical Engineering, Islamic Azad University-Semnan Branch, Semnan, Iran. \\ (Corresponding author's e-mail: yasharejavadi@yahoo.com; Tel: +98 9124402303, Fax: +98 \\ 231335 4030.) \\ Omid Afzali \\ MSc. Student, Department of Mechanical Engineering, Amirkabir University of Technology, \\ 424 Hafez Ave., Tehran, Iran. \\ Tel: +989352802818; Fax:+982166419736; Email: afzali_omid@yahoo.com \\ Mohammadreza Hadizadeh Raeisi \\ BSc. Student, Department of Mechanical Engineering, Amirkabir University of Technology, 424 \\ Hafez Ave., Tehran, Iran.
}

Tel: +989126782410; Fax: +982166419736; Email: m.r.hadizadeh.r@gmail.com

Mehdi Ahmadi Najafabadi

Associate Professor, Department of Mechanical Engineering, Amirkabir University of Technology, 424 Hafez Ave., Tehran, Iran.

Tel: +982164543431; Fax: +982166419736; Email: ahmadin@aut.ac.ir 


\section{ABSTRACT}

This paper investigates the nondestructive capability of ultrasonic waves in residual stress evaluation of dissimilar welded pipes. Longitudinal critically refracted $\left(L_{C R}\right)$ waves are employed to measure the residual stresses in a pipe-pipe joint of stainless steel 304 and carbon steel A106. Measuring the acoustoelastic constant is usually accomplished through the tensile test which needs cutting the tested material to extract tensile test specimens. However, the cutting process on the main tested pipe is not considered here to complete ultrasonic measurement nondestructively. Instead, a dissimilar welded plate with the same welding specification, joint geometry, thickness and the same dissimilar materials is used to extract tensile test samples. The measured acoustoelastic constant of the plate along with the measured time of flight of the $L_{C R}$ wave on the pipe, are utilized for ultrasonic stress measurement. A finite element model of welding process validated by hole-drilling method is used to verify the ultrasonic results. The results show good agreement between finite element and ultrasonic measurements in the pipe measured without any destructive process.

Keywords: Finite Element Welding Simulation; Dissimilar Welding; Nondestructive Stress Measurement; Residual Stress; $L_{C R}$ waves; Acoustoelastic Constant.

\section{1- INTRODUCTION}

Dissimilar metal joints between pipes of ferritic and austenitic steels are extensively utilized in engineering structures such as steam generators of power plants. Failure analyses on dissimilar welded joints have shown that the failures usually occur in the heat affected zone (HAZ) on the ferritic steel side of such structures [2]. Residual stresses present in the welded joints are an important contributing factor of the failures.

Nondestructive measurement of residual stress is important to optimize the structures' design and control their mechanical strength. One of the promising directions in the development of nondestructive techniques for residual stresses measurement is the application of ultrasound [3]. Ultrasonic stress measurement is based on the linear relation between the ultrasonic wave velocity and the material stress. This relationship, within the elastic limit, is the acoustoelastic effect which states that time of flight related to the ultrasonic wave varies linearly with stress. The longitudinal critically refracted $\left(L_{C R}\right)$ wave is a longitudinal ultrasonic wave which can travel parallel the surface. It is shown by Egle and Bray [4] that sensitivity of the $L_{C R}$ waves to the strain is highest among the other types of ultrasonic waves. Among the first theoretical studies about $L_{C R}$ waves, that of Basatskaya and Ermolov [5] was based on a 2D analytical calculation in the case of harmonic waves. The typical acoustic field of $L_{C R}$ wave was illustrated by Langenberg et al. [5] in 1990. They utilized a numerical scheme for the computation of elastodynamic wave fields in nearly arbitrary environments, called elastodynamic finite integration technique (EFIT), to predict the $L_{C R}$ wave features quantitatively. Since this last date, there is no new research works in the field of combining numerical calculation and experimental validation related to the $L_{C R}$ waves. Recently, Chaki et al. [7] have numerically analyzed the $L_{C R}$ waves. They employed a time domain finite element (FE) simulation to interpret the experimental signals, whereas simulations in frequency domain were carried out to characterize the angular ultrasonic beam in a bulk sample.

This study also investigates a combination of finite element simulation and the $L_{C R}$ waves for residual stress measurement of a dissimilar pipe.

Despite of rarely numerical investigation related to the $L_{C R}$ method, the applications of these waves for the stress measurement are considered in many studies. Bray and Junghans [8] studied the applications of the $L_{C R}$ ultrasonic technique in evaluation of post-weld heat treatment in steel plates. They also measured temperature effect on the time of flight in $L_{C R}$ waves. Residual stress measurements in steel plates and welds using $L_{C R}$ waves were done by Leon-Salamanca and Bray [9]. They have investigated the effect of stress relieving on the ultrasonic waves. Tanala et al [10] determined acoustoelastic constant of $316 \mathrm{~L}$ stainless steel and 5086 aluminum. The $L_{C R}$ measurement was done in immersion mode by Belahcene and $L_{u}$ [11] to measure 
residual stress of S355 welded steel plate. They used hole-drilling method to verify the ultrasonic results. They also measured the penetration depth of $L_{C R}$ by using a gauge block with different depth groove. The results showed that the penetration depth of $L_{C R}$ wave was equivalent to one wavelength. Walaszek et al [12] measured the acoustoelastic constant directly in the weld by preparing a tensile test sample from the melted zone in the P460 and P265 steel. Lu et al [13] measured welding residual stresses in the Q-235 steel and 2219 Al plates. A comparison was also made with the result of finite element method. However, they did not experimentally measure the stresses on the weld zone. Palanichamy et al [14] measured the residual stresses in austenitic stainless steel weld joints using ultrasonic technique. Before the micro-structural investigation by Qozam et al. [15], the residual stresses evaluation in the steel welded plates, by the use of the $L_{C R}$ wave method, was only possible in the melted zone (MZ) and in the parent material (PM). While in the HAZ, the residual stresses were incorrectly evaluated due to its small width impeding the extraction of the calibration sample. They proposed a specific heat treatment to reproduce the microstructure of HAZ in samples extracted from the parent material. By measuring the acoustoelastic constant in these new samples (with reproduced microstructure) they could measure the acoustoelastic constant of the HAZ. They concluded that the microstructure affects on both the acoustoelastic constant and the free-stress time-of-flight $\left(t_{0}\right)$ while the correction of $t_{0}$ could correct the overestimated residual stresses in the HAZ and MZ zones from approximately 70 to $80 \%$.

An examination of the existing literature reveals a need for the investigation of ultrasonic stress measurement of a dissimilar joint. Furthermore, pipe stresses are measured ultrasonically in a limited scale probably because of practical difficulties. In all of the previous studies, the main tested structure was machined to extract the tensile test specimens for measuring the acoustoelastic constant. In this study, the cutting process on the main tested pipe is not considered to complete ultrasonic measurement nondestructively. Instead, a dissimilar welded plate with the same welding specification, joint geometry, thickness and the same dissimilar materials is employed. The plate is used to extract tensile test samples and calculate the acoustoelastic constant. The calculated constant can be employed to relate the measured time of flight of ultrasonic wave in the pipe to the stress, based on the acoustoelasticity relations. In this study, a comparison is made between the values of stresses evaluated by the ultrasonic measurements and those obtained from finite element analysis. The results of finite element welding simulation are validated by hole-drilling method.

\section{2- THEORETICAL BACKGROUND}

\section{2-1. $L_{C R}$ method}

The $L_{C R}$ method uses a special longitudinal bulk wave mode, as shown in Fig. 1, mainly propagating beneath the surface at a certain depth. When a longitudinal wave passes through an interface between two materials, there is an incident angle that makes the angle of refraction for the wave equal to $90^{\circ}$. This incident angle (first critical angle) is calculated to be $28^{\circ}$ for the combination of PMMA (Plexiglas) and steel (as shown in Fig. 1).

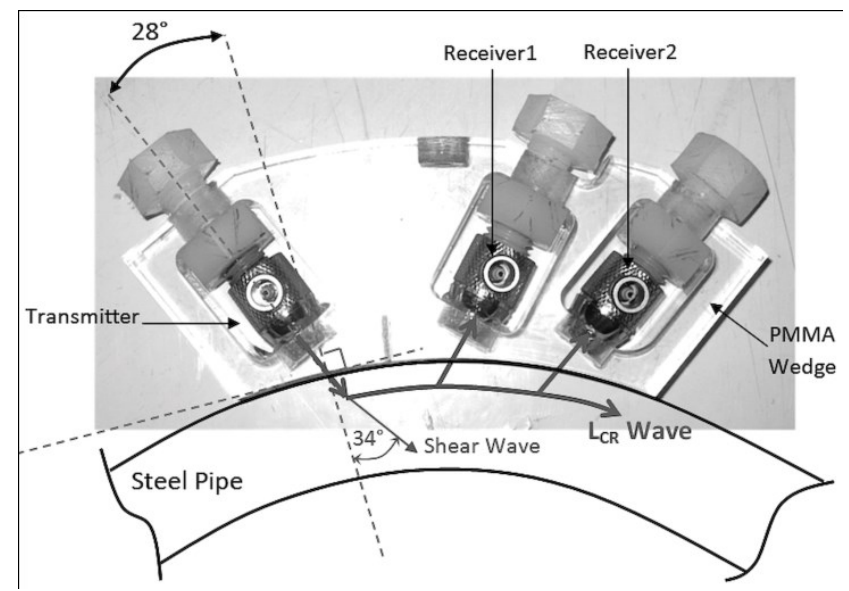

Fig. 1 Ultrasonic transducers and PMMA wedge to propagate the $L_{C R}$ Wave in the Steel Pipe 
The relationship between the time of flight (TOF) of the longitudinal waves which travel parallel to the load direction and the stress is expressed by the following equation:

$$
\sigma=\frac{E}{L t_{0}}\left(t-t_{0}\right)
$$

In Eq. (1), $\sigma$ is the stress, $E$ is the elasticity modulus, $t$ is measured TOF on the investigated material between Receiver 1 and Receiver $2, t_{0}$ is TOF in the free stress material between Receiver 1 and Receiver 2 and $L$ is the dimensionless acoustoelastic constant for $L_{C R}$ waves which should be determined through the uniaxial tensile test.

\section{2-2. Finite Element Welding Simulation}

Welding simulation by Finite Element (FE) has become a popular method for the prediction of welding residual stresses and deformations. Earlier studies of welding simulation accounted for the nonlinearities because of temperature dependent material properties and plastic deformations [16]. The majority of those studies, due to weakness in the computational capabilities of the previous computers, were limited to two-dimensions on the plane perpendicular to the welding direction. Good agreements have been observed between the numerical predictions and experimental results $[16,17]$ which encourage using FE welding simulation in residual stress evaluation.

Numerical simulation of the welding residual stresses needs, to take account of the mechanical behavior of welds, which is sensitive to the close coupling among heat transfer, microstructure evolution and thermal stress analysis. The phenomena involved in the heat input such as arc, material interactions, as well as, fluid dynamics in the weld pool are not precisely described. From the thermo-mechanical point of view, the heat input can be seen as a volumetric or surfaced energy distribution, and the fluid flow effect, which leads to homogenize the temperature in the molten area, can be simply taken into account by increasing the thermal conductivity over the melting temperature. Heat transfers in solids are described by the heat equation as following:

$\rho \frac{d H}{d t}-\operatorname{div}(k \nabla T)-Q=0$

$$
k \nabla T . n=q(T, t) \text { on } \partial \Omega_{q}
$$

$$
T=T_{p}(t) \quad \text { on } \partial \Omega_{t}
$$

In Eq. (2-4), $\rho, H, k$ and $T$ are density, enthalpy, thermal conductivity and temperature respectively. $Q$ represents the internal heat source. In Eq. (3), $\mathrm{n}$ is the outward normal vector of domain $\partial \Omega$ and $q$ is the heat flux density that can rely on temperature and time to model convective heat exchanges on the surface and $T_{p}$ is a prescribed temperature.

The heat input is represented by an internal heat source. In this study, the double ellipsoid heat source pattern proposed by Goldak et al. [19] is utilized, as shown in Fig. 2. As it is seen, the front half of the heat source is the quadrant of one ellipsoidal source, and the rear half is the quadrant of another ellipsoid.

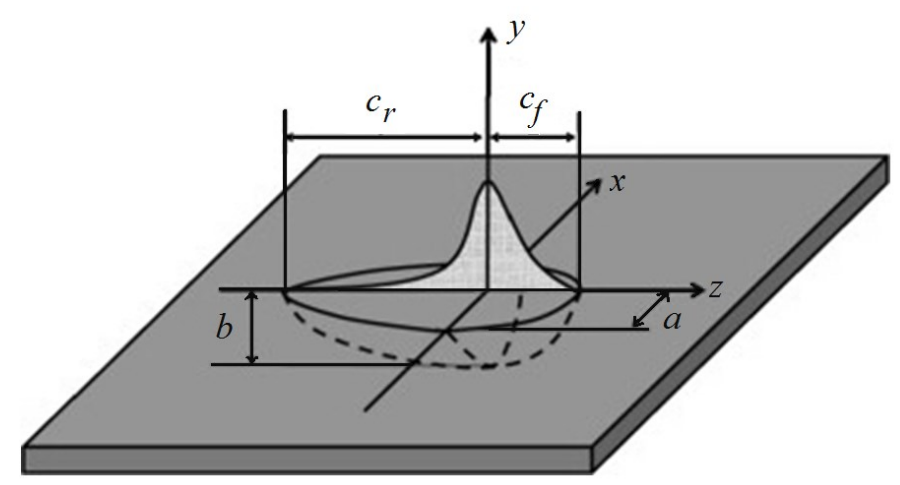


Fig. 2 Double ellipsoid heat source configuration used for FE simulation of welding heat source [19]

The Goldak equations for the front and rear heat source are expressed by the Eq. 5 and Eq. 6 respectively:

$$
\begin{aligned}
& q_{f}(x, y, z)=\frac{6 \sqrt{3} f_{f} Q}{a b c_{f} \pi^{3 / 2}} e^{\left(-3 x^{2} / a^{2}\right)} e^{\left(-3 y^{2} / b^{2}\right)} e^{\left(-3 z^{2} / c^{2}\right)} \\
& q_{r}(x, y, z)=\frac{6 \sqrt{3} f_{r} Q}{a b c_{r} \pi^{3 / 2}} e^{\left(-3 x^{2} / a^{2}\right)} e^{\left(-3 y^{2} / b^{2}\right)} e^{\left(-3 z^{2} / c^{2}\right)}
\end{aligned}
$$

In Eq. (5-6), $x, y$ and $z$ are the local coordinates of the double ellipsoid model aligned with the welded plate; $f_{f}$ and $f_{r}$ are parameters which give the fraction of the heat deposited in the front and rear parts, respectively. $Q$ is the welding energy which is calculated by knowing the welding current and voltage and considering the arc efficiency. The parameter $a$ is one-half the width of melted zone; $b$ is depth of the melted zone; $c_{f}$ and $c_{r}$ are the front and behind section dimensions of the heat source respectively. The front section dimension of the heat source $\left(c_{f}\right)$ is assumed equal to $a$ and the rear section $\left(c_{r}\right)$ is equal to $4 \times a$. The relations $2 /\left(1+c_{r} / c_{f}\right)$ and $2 /\left(1+c_{f} / c_{r}\right)$ are used to calculate the $f_{f}$ and $f_{r}$ respectively. The moving heat source is modelled by a user subroutine in the ANSYS software.

The mechanical analysis is based on the usual equations of the static equilibrium. As the plastic dissipation is neglected in the thermal analysis, thermal and mechanical analysis can be treated separately. The temperature field computed by the thermal analysis, is utilized in the mechanical analysis. The materials are supposed to follow an elastic-plastic behavior with isotropic hardening. The material parameters such as Young's modulus, poisson's ratio, yield stress, strain hardening and heat expansion coefficient are temperature dependent.

Material modeling has always been a serious issue in the simulation of welding because of the scarcity of material data at elevated temperatures. Some simplifications and approximations are typically introduced to cope with this problem. The simplifications are necessary, not only is there the lack of data, but also there are numerical problems against modeling the actual high-temperature behavior of the material [20]. The material properties for stainless steel 304 and carbon steel A106 are shown in Fig. 3 and Fig. 4 which are taken from Lindgren [21] and P. Chang [22] respectively. In this figure, $\alpha$ is coefficient of linear thermal expansion, $c$ is the specific heat, $E$ is the elastic modulus, $k$ is the thermal conductivity and $\sigma_{y}$ is the yield stress. The filler metals are determined with help to Schaeffler Diagram [23].

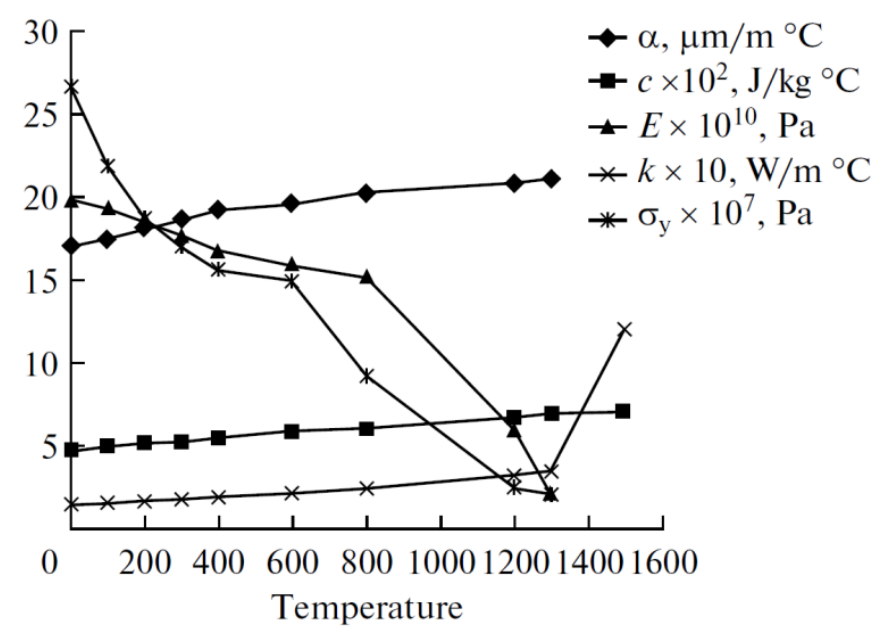

Fig. 3 Material properties for stainless steel 304 [21] 


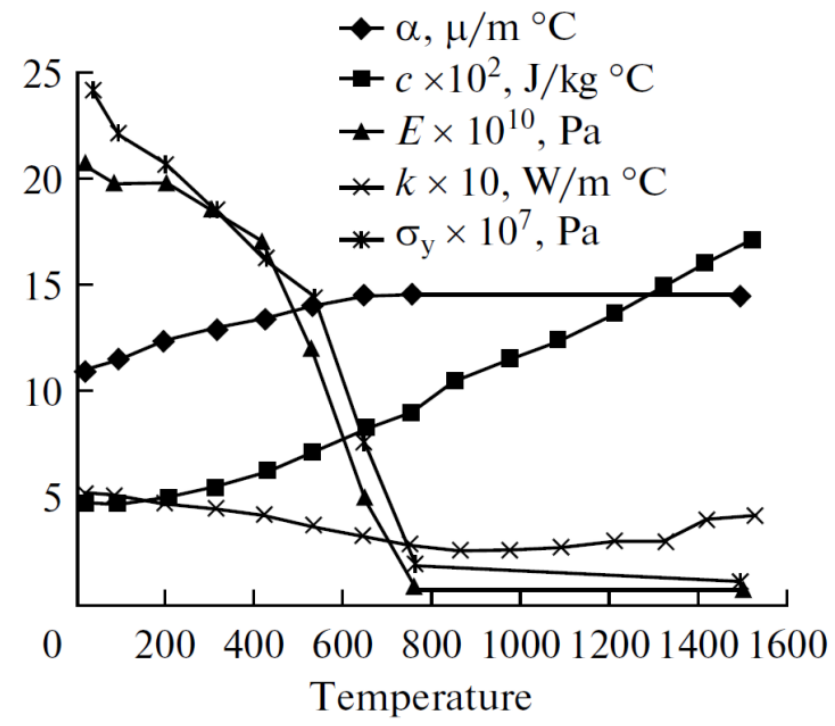

Fig. 4 Material properties for carbon steel A106-B [22]

The problem is formulated as a successively coupled thermal stress analysis. First, a non-linear thermal analysis is performed to calculate the temperature history of the entire domain. Then, the results of the thermal analysis are applied as a thermal body load in a non-linear mechanical analysis which determines residual stress and distortion. The finite element (FE) models for both thermal and structural analysis are the same. The general-purposed FE program ANSYS is used for the analyses. A full Newton-Raphson iterative solution technique with direct sparse matrix solver is employed for obtaining a solution. During the thermal analysis, the temperature dependent material properties alter rapidly. Thus, the full Newton-Raphson technique by using modified material properties is believed to give more precise results.

A conventional technique named "Element Birth and Death" [24] is utilized for modelling of the deposited weld. A complete FE model is generated in the begining of the analysis. However, all elements representing the deposited weld except elements for the tack welds are deactivated by assigning them a very low stiffness. During the thermal analysis, all the nodes of deactivated elements (excluding those shared with the base metal) are also fixed at room temperature till the birth of the respective elements. Deactivated elements are reactivated sequentially when they come under the effect of the welding torch. Linear elements are preferred rather than higher-order elements in non-linear problems of this type [25]. Here, eight-noded-brick elements with linear shape functions are used in the FE modeling. The basic FE model of pipes is shown in Fig. 5 where pipe sides have been meshed similarly. The interface elements are employed to connect fine mesh (used to mesh weld zone and near points) to coarse mesh (used to mesh points away from the weld). There are 122616 nodes and 93504 elements in the model while about 25920 nodes and elements are positioned in the weld region. 


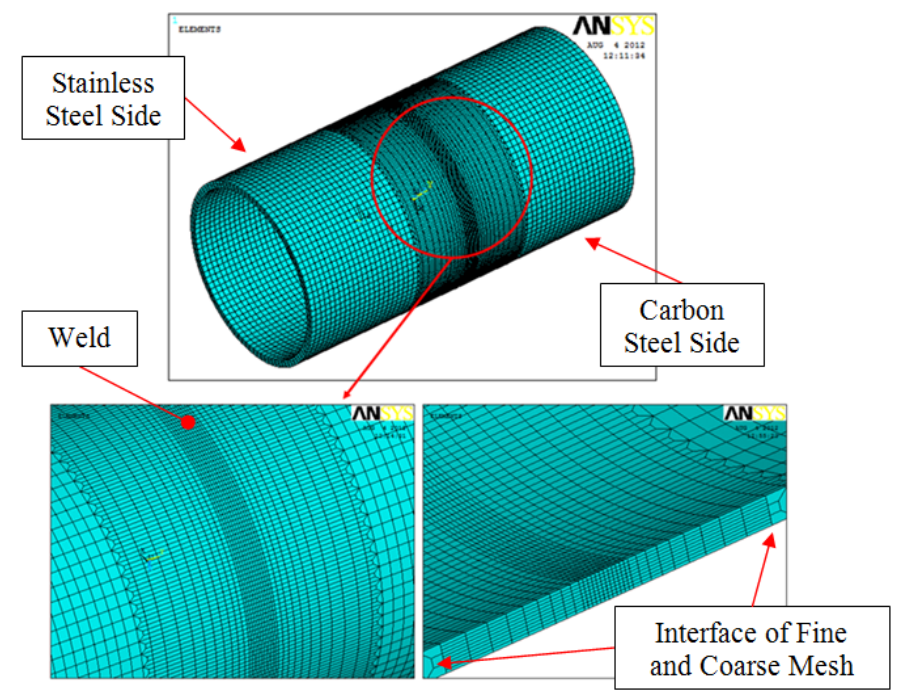

Fig. 5 Basic FE model of dissimilar pipe

\section{3- EXPERIMENTAL PROCEDURES}

\section{3-1. Sample Description}

A stainless steel (TP 304) pipe is welded to a carbon steel (A106) pipe whereas their thickness and diameter are equal to $8 \mathrm{~mm}$ and $220 \mathrm{~mm}$ respectively (Fig. 6). The root pass is welded by gas tungsten arc welding (GTAW) process while shielded metal arc welding (SMAW) is used to accomplish the other passes according to the Table 1 . The geometry of joint is $\mathrm{V}$-groove $\left(90^{\circ}\right.$ included angle) with $4 \mathrm{~mm}$ gap.

Two dissimilar plates are also welded while the material, thickness, welding specification, gap and groove geometry is same as the main tested pipe. The plates are employed in extracting the tensile test samples and measuring the acoustoelastic constant.

The ultrasonic transducers should pass the weld (as shown in Fig. 6) to scan the tested pipe hence, the weld reinforcement is removed by using a $30000 \mathrm{rpm}$ hand grinding machine to facilitate ultrasonic measurements. The rising temperature is controlled during the grinding process by using water cooling to prevent generation of thermal stresses. However, the welding process of pipe is considered as a flat welding (with minimum height of welding reinforcement) to minimize the material that should be removed by grinding. Furthermore, the depth of each layer during the grinding process is kept very thin. Flat weld along with fine grinding help to minimize new mechanical stresses generated by grinding machine hence, redistribution of stresses due to grinding process is negligible.

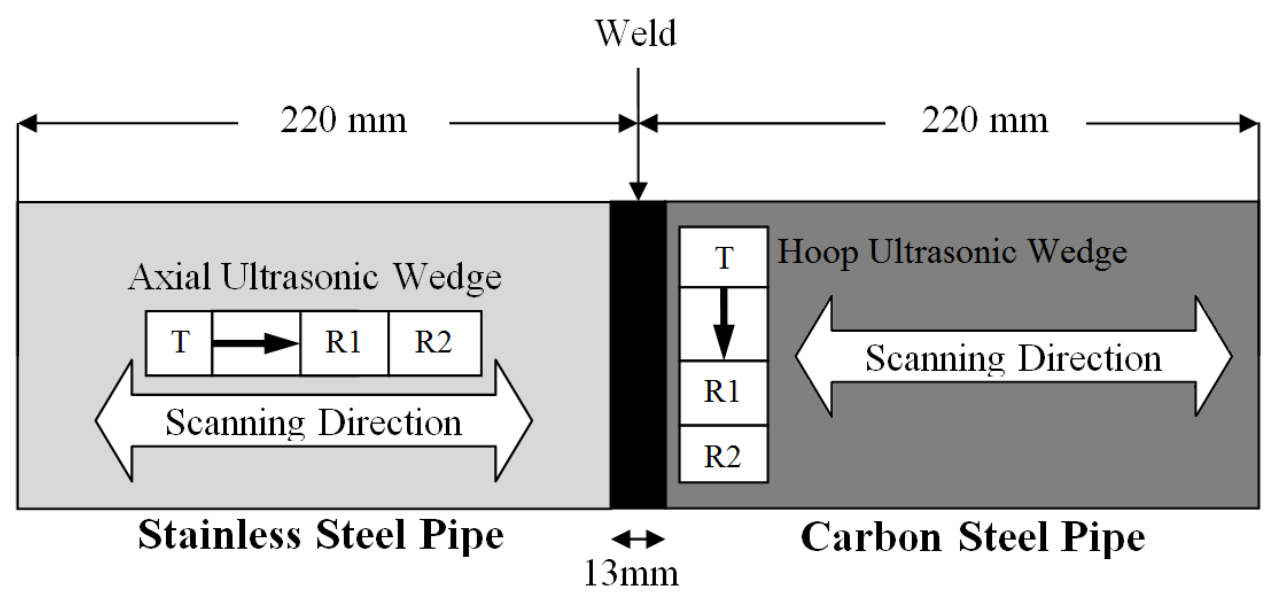


Fig. 6. Pipe Dimensions and Ultrasonic Wedge

Table 1 Welding specifications of Dissimilar Welded Pipe

\begin{tabular}{cccccc}
\hline Pass No. & $\begin{array}{c}\text { Welding } \\
\text { Method }\end{array}$ & $\begin{array}{c}\text { Welding } \\
\text { Voltage }(\mathrm{V})\end{array}$ & $\begin{array}{c}\text { Welding Current } \\
(\mathrm{A})\end{array}$ & $\begin{array}{c}\text { Welding Speed } \\
(\mathrm{cm} / \mathrm{min})\end{array}$ & Filler Material \\
\hline 1 (root pass) & GTAW & 9 & 95 & 3.5 & ER308L \\
2 & SMAW & 27 & 115 & 22 & E 308L-16 \\
3 & SMAW & 27 & 145 & 17 & E 308L-16 \\
\hline
\end{tabular}

\section{3-2. Measurement Device}

The measurement device, shown in Fig. 7, includes an ultrasonic box, computer and time of flight (TOF) measuring element. The ultrasonic box is a $100 \mathrm{MHz}$ (sampling frequency) ultrasonic testing device which has synchronization between the pulser signal and the internal clock, which controls the A/D converter. Its post trigger (delay) time has stability within the range of 1 ns which is achieved by using an internal clock with frequency of $1 \mathrm{GHz}$. The high stability of ultrasonic box is claimed by the manufacturer however, this stability is measured experimentally and has been confirmed. Furthermore, a MATLAB subroutine is employed to increase the resolution to $0.1 \mathrm{~ns}$. TOF measuring element includes three normal transducers assembled on an integrated wedge to measure the time of flight. A poly methyl methacrylate (PMMA) material, under the trademark Plexiglas, is cut by laser to construct the wedge. However, two types of wedge are needed to measure hoop and axial stress separately (Fig. 8). Surface curvature of pipe is taken into account in laser cutting of the bottom surface in both of the wedges. A three-probe arrangement is utilized, with one sender and two receivers in order to eliminate the effects of environment temperature on the travel time. Three normal transducers with the same frequency are used where their nominal frequencies are $2 \mathrm{MHz}$ and the diameter of the piezoelectric elements is $6 \mathrm{~mm}$. The measurement devices are utilized to measure TOF on the pipe and these data along with the measured acoustoelastic constant of plate will be used to calculate the pipe's residual stresses based on Eq. (1). 


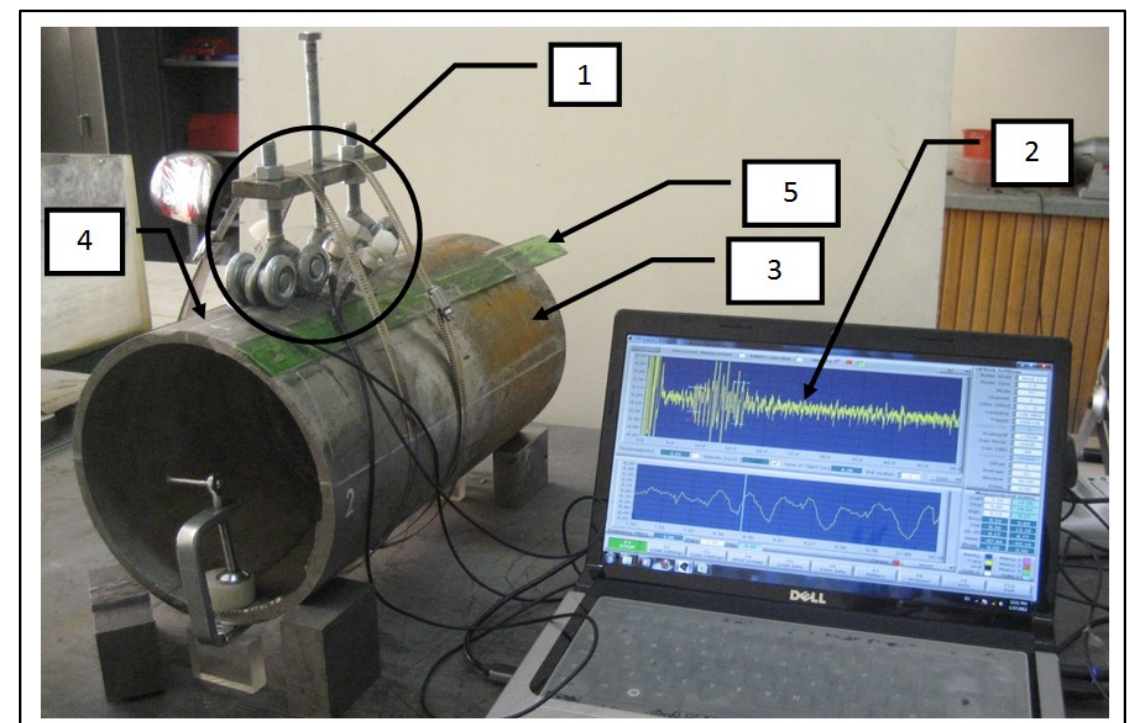

(a)

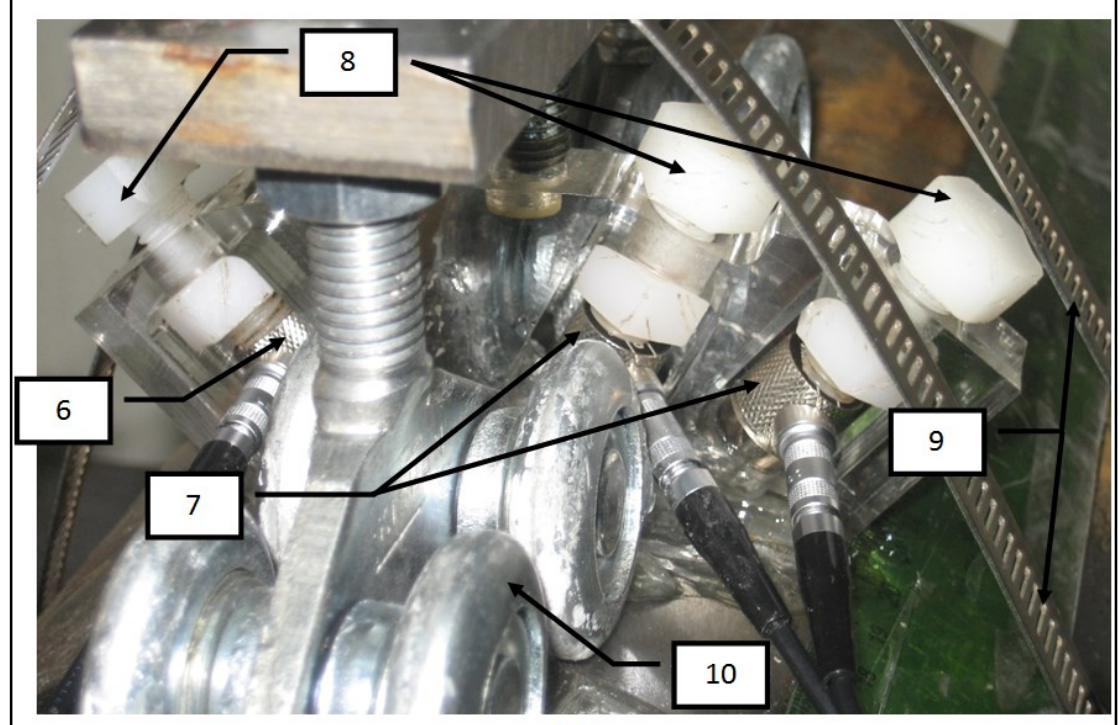

(b)

$\begin{array}{ll}\text { 1- TOF Measuring Element } & \text { 6- } \text { Transmitter Transducer } \\ \text { 2- Ultrasonic Software } & \text { 7- Receiver Transducers } \\ \text { 3- Carbon Steel Pipe } & \text { 8- Plastic Screws } \\ \text { 4- Stainless Steel Pipe } & \text { 9- Holder } \\ \text { 5- Ruler } & \text { 10- Driving Wheel }\end{array}$

Fig. 7 Ultrasonic Measurement Devices (a) and TOF Measuring Element (b) 


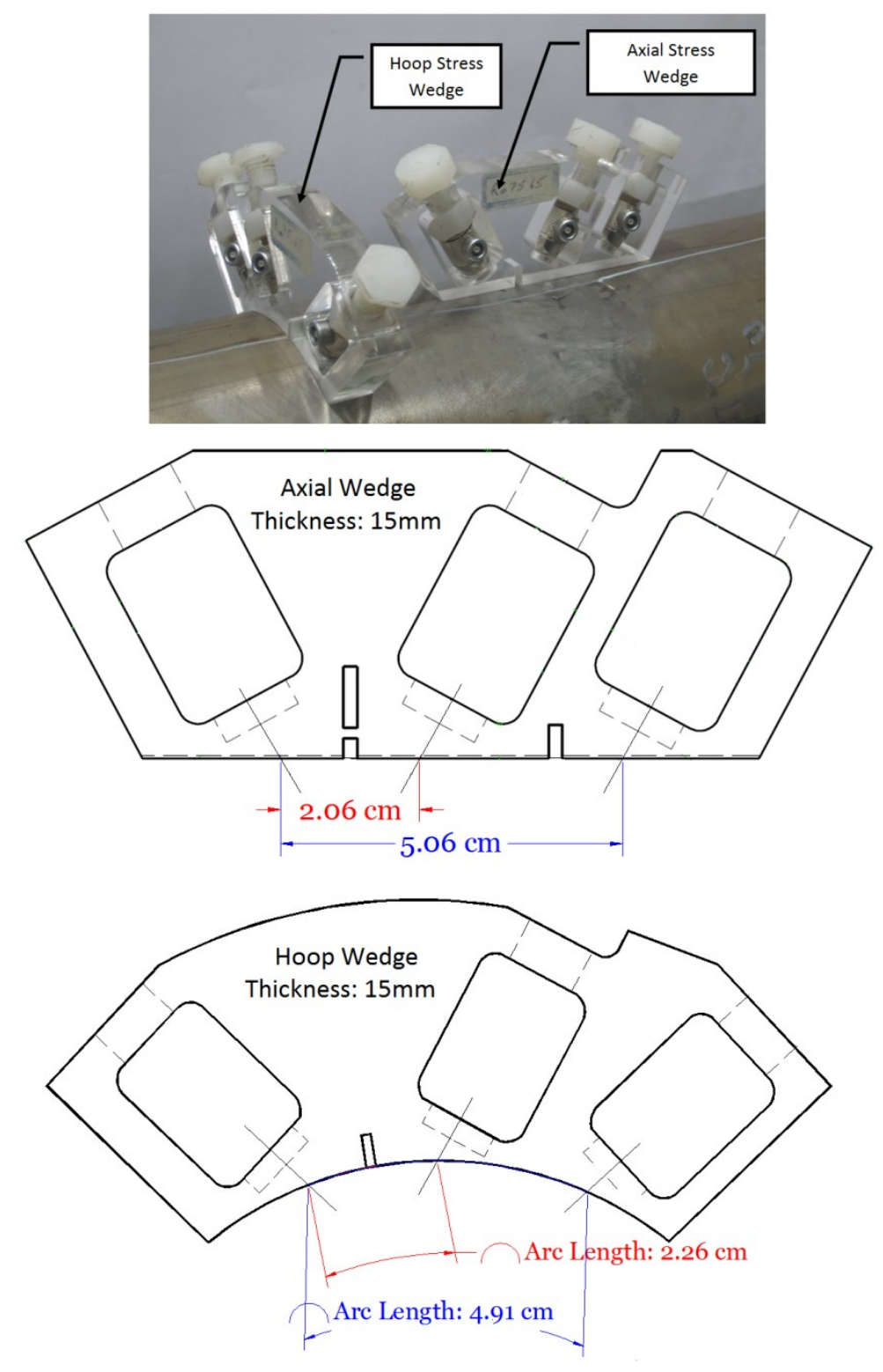

Fig. 8 Hoop and Axial Wedge Design

\section{3-3. Determination of $L_{C R}$ Penetration Depth}

When the $L_{C R}$ technique is used for an application with limited wall thickness, the depth of the $L_{C R}$ wave penetration is expected to be a function of frequency. However, there is no definite relation between $L_{C R}$ depth and frequency. Hence, the $L_{C R}$ depth should be measured experimentally. A variable depth groove is cut in a plate with the same material and thickness as those of the tested dissimilar materials to produce a barrier to physically prevent the $L_{C R}$ wave from reaching the receiver transducer. It is found that a $2 \mathrm{~mm}$ depth groove can completely prevent a $2 \mathrm{MHz} L_{C R}$ wave to pass, which indicates that the penetration depth of such a $L_{C R}$ wave is $2 \mathrm{~mm}$ in both stainless and carbon steel plate.

\section{3-4. Evaluation of the Acoustoelastic Constants}

To evaluate the acoustoelastic constant $(L)$, the tensile test samples are taken from both sides of the plates. Three rectangular tension test specimens are extracted from stainless steel side, carbon steel side and the weld zone separately. The samples are stress relieved (heat treated at $450^{\circ} \mathrm{C}$ for 2 hours then cooling in the furnace) and the value $t_{0}$ is measured directly from the 
stress-free samples. To evaluate the residual stress according to the Eq. (1), the acoustoelastic constant is then deduced experimentally from a uniaxial loading calibration test (see Fig. 9). The measurement devices used to measure $t_{0}$ and $L$ is the same as used during the TOF measuring of the pipe while a flat wedge is employed here.

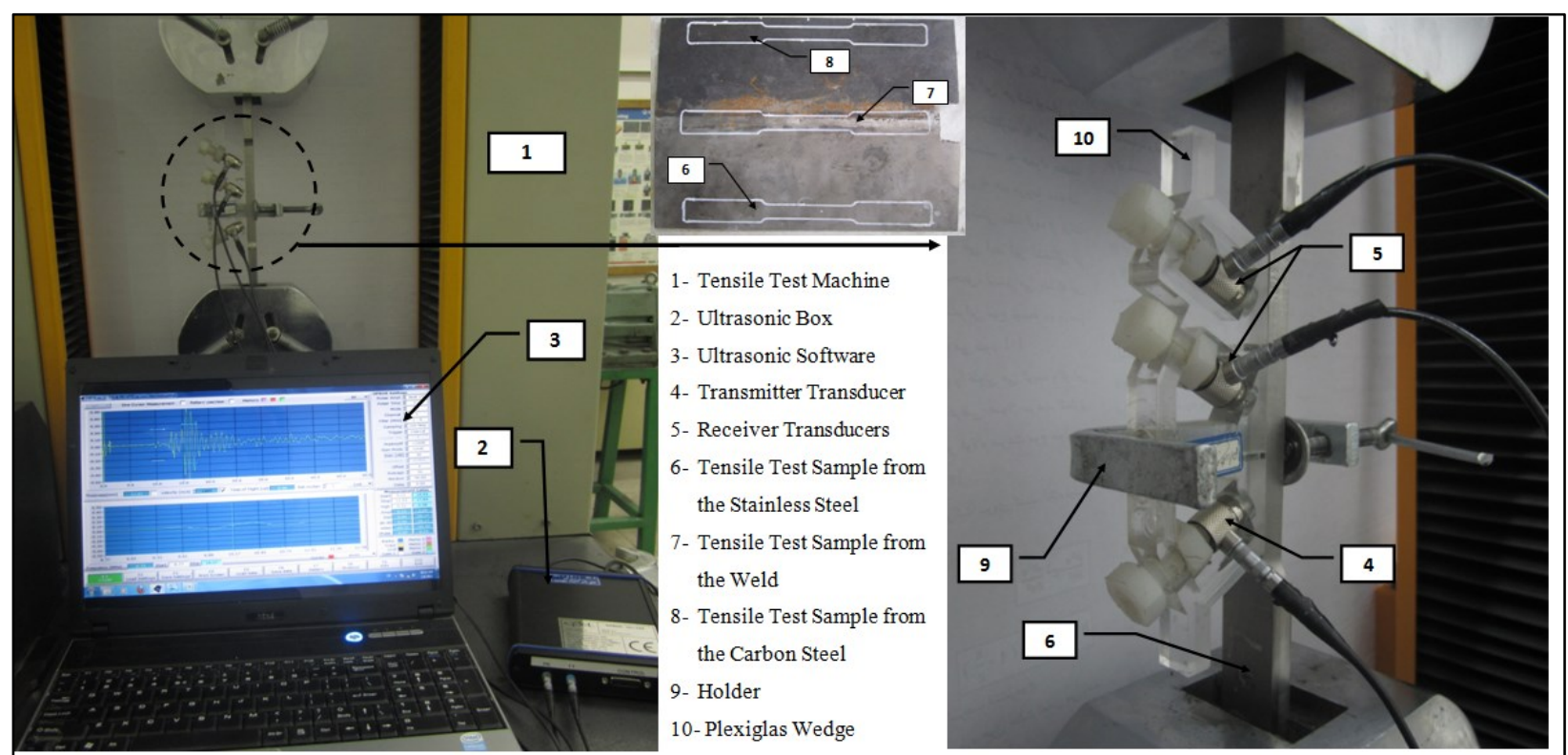

* Tensile test is applied on samples number 6,7 and 8 to measure acoustoelastic constant of stainless steel, the weld and carbon steel respectively. The above figure shows measuring the acoustoelastic constant of stainless steel. The tensile test specimen (number 6 in the right picture) should be replaced by number 7 and 8 to measure acoustoelastic constant of weld and carbon steel respectively.

Fig. 9 Experimental setup to evaluate acoustoelastic constant during tensile test

\section{4- RESULTS AND DISCUSSION}

The results of tensile test are shown in Fig. 10 where the slope of the lines represents $L$ acoustoelastic constants. The elastic modulus $(E)$ is measured $196 \mathrm{GPa}, 199 \mathrm{GPa}$ and $209 \mathrm{GPa}$ through tensile test of the stainless steel, weld and carbon steel sample respectively. All the measured data are related to the plate and will be used in Eq. (1) to calculate residual stresses of the tested pipes. The slope of the lines is equal to $2.15,2.38$ and 2.58 related to the stainless steel, carbon steel and weld region respectively (Fig. 10). It means that the acoustoelastic constant of the carbon steel is higher than stainless steel while the weld constant is more than the both.

\section{Acoustoelastic Constant}

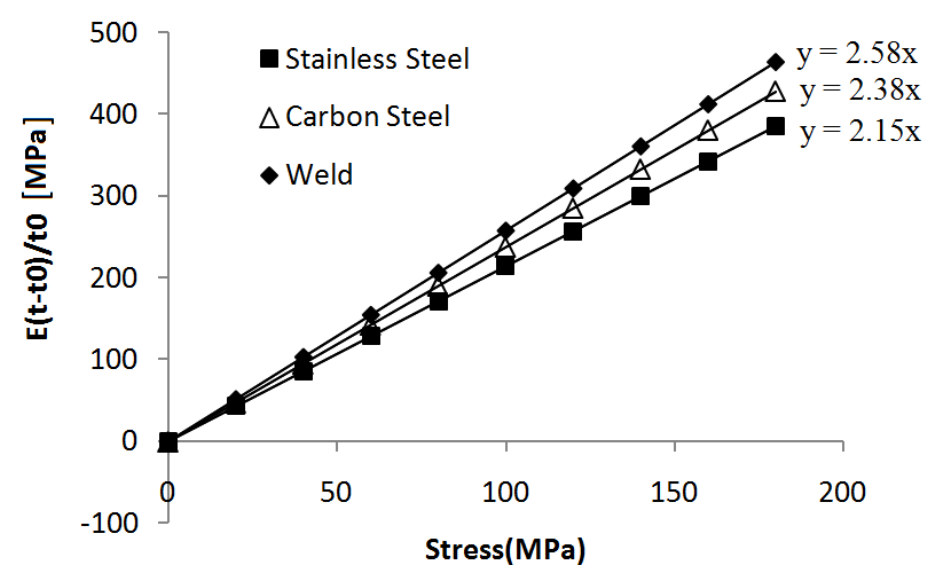




\section{Fig. 10 Result of Tensile test to evaluate acoustoelastic constant}

In this study, the 3D finite element analysis for welding simulation is employed to predict the welding residual stresses of the dissimilar pipe. Fig. 11 show finite element results for axial and hoop residual stresses related to outer surface of the pipe. Axial residual stresses of the outer surface are compressive, while the hoop residual stresses are tensile in the weld zone. The distribution of residual stress is not symmetric and the maximum of residual stress is observed in the stainless steel side of the pipe for all of the results. It is justified by higher yield stress of stainless steel ( $265 \mathrm{MPa}$ ) in comparison with the carbon steel side $(240 \mathrm{MPa})$. The hole-drilling test is performed in 3 different points on the outer surface to verify the FE model. The holedrilling method gives the average of residual stresses measured along the $2 \mathrm{~mm}$ depth hole. Hence, the average results of FE residual stresses in 0-2 $\mathrm{mm}$ from the surface are compared with those measured by the hole-drilling method while a good agreement can be observed.

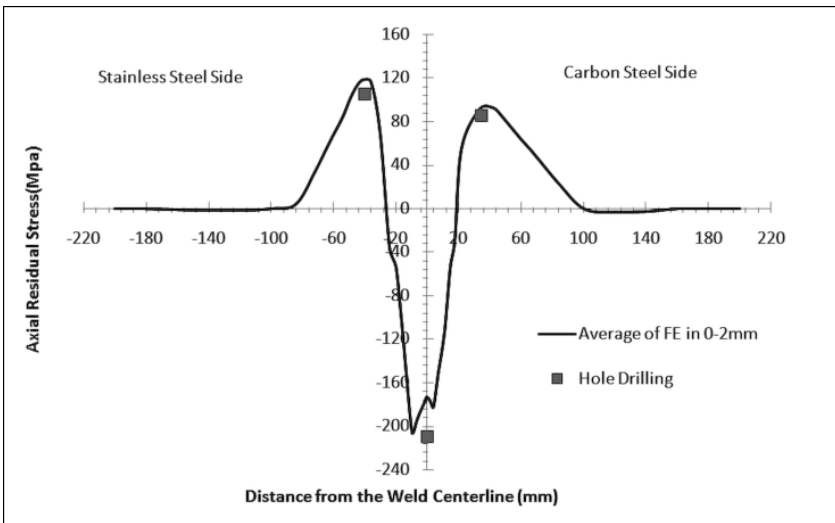

(a)

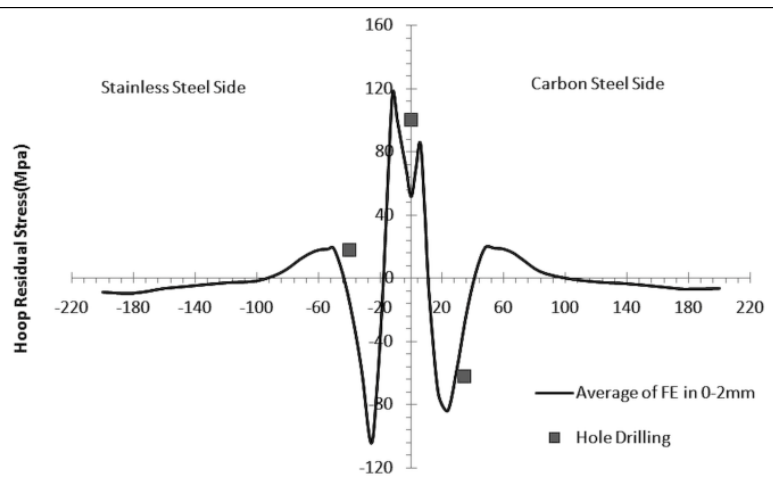

Distance from the Weld Centerline $(\mathrm{mm})$

(b)

Fig. 11 Average of FE Results and its comparison with Hole-drilling method related to the a) Axial Residual Stress and b) Hoop Residual Stress

The residual stresses are also measured with $L_{C R}$ ultrasonic waves. It should be noted that ultrasonic method measures the average of stresses in determined depth. It means that the $2 \mathrm{MHz} L_{C R}$ wave travels within $2 \mathrm{~mm}$ beneath the surface and gives the average of residual stress in this zone. Therefore, in the FE method, the average of residual stresses for all the nodes located in the range of 0-2 mm under the surface are used to compare with those obtained from ultrasonic measurements.

Furthermore, it also averages the stresses between the two receivers which are placed $30 \mathrm{~mm}$ apart (Fig. 8) while moving along the axial direction. It means that, when the receivers are placed across the weld zone, it averages the stresses in weld bead (melted zone or MZ), heat affected zone (HAZ) and some part of the parent material (PM). Moving step of scanning transducers is reduced to $0.5 \mathrm{~mm}$ to overcome the averaging problem in this zone. The moving step reduction slightly helps to distinguish between TOF influenced by MZ, HAZ and PM region. The averaging is also considered in extracting the residual stresses from FE results. However, this problem leads to measuring error in the axial stress results which will be discussed more in Fig. 14.

The measured TOF of pipe along with the measured acoustoelastic constant of plate are utilized in Eq. (1) to calculate the residual stresses by ultrasonic method. The FE results and ultrasonic measurements are compared in the Fig. 12 and Fig. 13. 


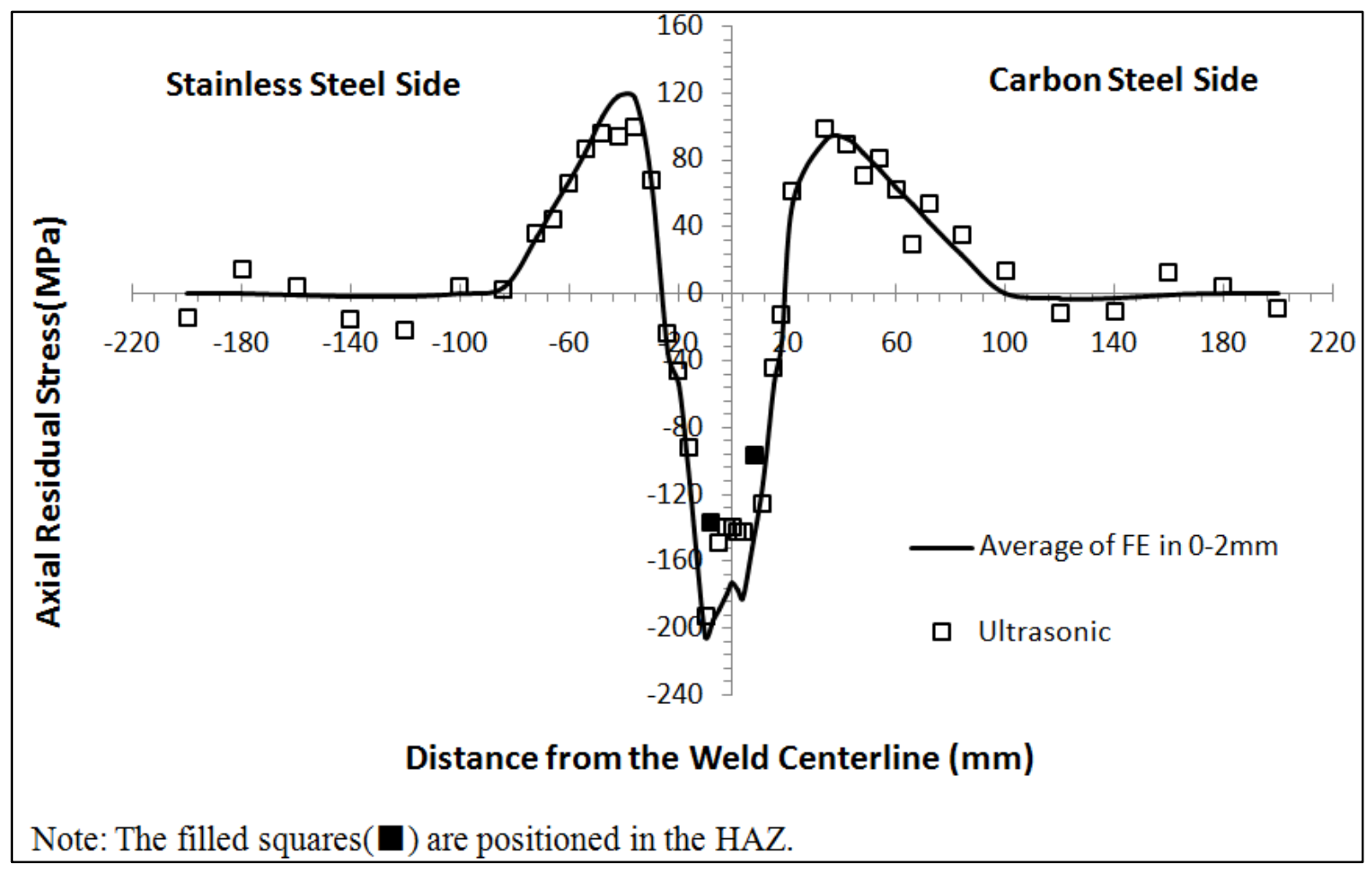

Fig. 12 Comparison of FE and Ultrasonic Results related to the Axial Residual Stress 


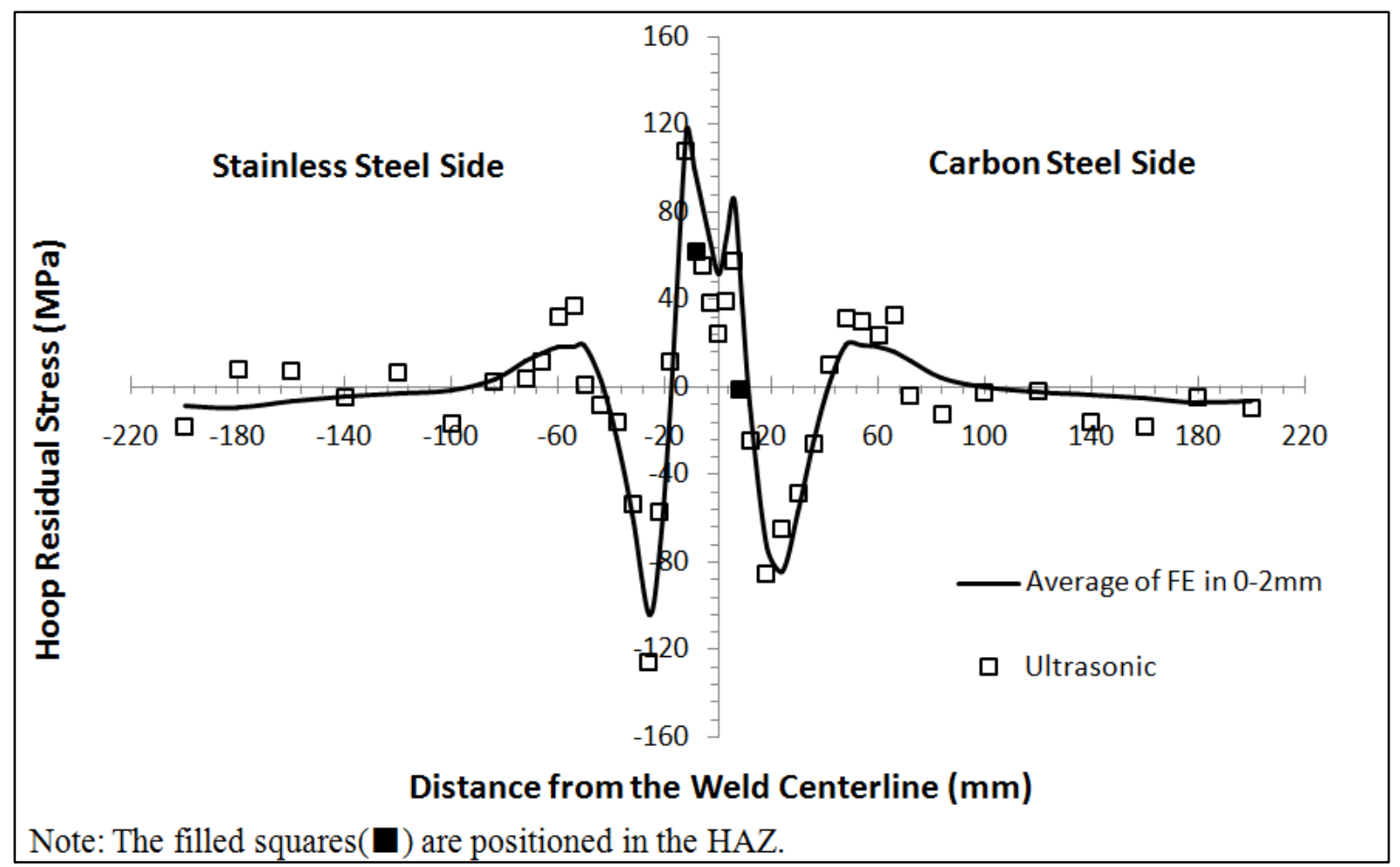

Fig. 13 Comparison of FE and Ultrasonic Results related to the Hoop Residual Stress

The results of ultrasonic measurements demonstrate an acceptable agreement with finite element analysis of the pipe. The disagreement between ultrasonic and FE results is altered according to the measured zone while the maximum is in the heat affected zone (HAZ). There are two filled squares in Fig. 12 and Fig. 13 which are located in the HAZ. The disagreement between FE and ultrasonic results for these points are about $60 \mathrm{MPa}$ and $40 \mathrm{MPa}$ associated with the axial and hoop stresses respectively. Since the dimension of $\mathrm{HAZ}$ is not enough to extract the tensile test sample, the acoustoelastic constant is not measured in this zone. Therefore, the acoustoelastic constant of the weld zone is used to calculate residual stresses of the HAZ which set off higher error in stress measurement. Similar measurement error is also observed by A. Santos et al [26] where the paper shows that not using the correct properties of the melted zone causes unexpected stress magnitudes. The disagreement between $\mathrm{FE}$ and ultrasonic results of the weld zone is about $40 \mathrm{MPa}$ and $30 \mathrm{MPa}$ corresponding to the axial and hoop stresses respectively.

Since the acoustoelastic constant of the weld zone is experimentally measured (number 7 in Fig. 9), it was expected that there is not high disagreement between FE and ultrasonic results in the weld. The high measuring error can be justified by difference which exists between measured acoustoelastic constant of the plate and non measured acoustoelastic constant of the pipe. The welding parameters (welding voltage, welding current, welding speed and joint dimensions) are kept the same during the welding process of the plate and pipe. However, the nature and technique of circumferential welding is different from straight welding which leads to difference between the acoustoelastic constant of pipe and plate.

The disagreement for the parent material zone does not exceed than $\pm 25 \mathrm{MPa}$ which is about $10 \%$ of yield strength of the tested materials. The maximum of disagreement between FE and ultrasonic results are listed in Table $\mathbf{2}$ for each three zone.

Table 2 Maximum disagreement between Ultrasonic and FE results

\begin{tabular}{l|lcc}
\hline & Parent Material & HAZ & Weld \\
\hline $\begin{array}{l}\text { Maximum disagreement between } \\
\text { Ultrasonic with FE results of the Axial } \\
\text { Residual Stress }\end{array}$ & $24 \mathrm{MPa}$ & $59 \mathrm{MPa}$ & $40 \mathrm{MPa}$ \\
& & &
\end{tabular}




\begin{tabular}{l|lll} 
Maximum disagreement between & $21 \mathrm{MPa}$ & $39 \mathrm{MPa}$ & $30 \mathrm{MPa}$ \\
Ultrasonic with FE results of the & & \\
Hoop Residual Stress & & \\
\hline
\end{tabular}

The difference between FE results and stresses measured by using ultrasonic method are shown in Fig. 14 and Fig. 15 related to the axial and hoop stress respectively. The yield strength of materials is used as denominator to calculate the percentage differences.

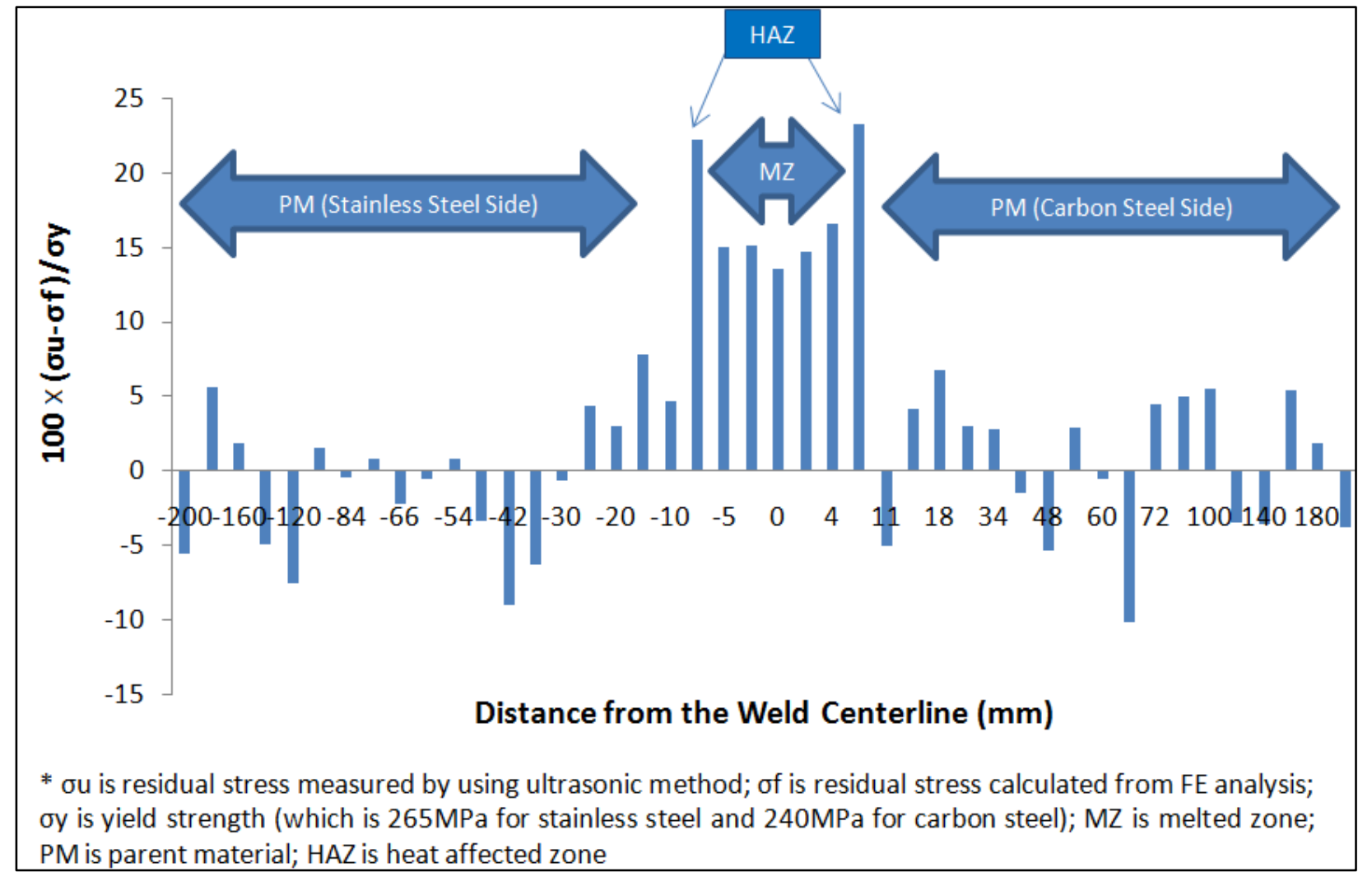

Fig. 14 Percentage difference between FE results and ultrasonic measurement related to the axial stresses 


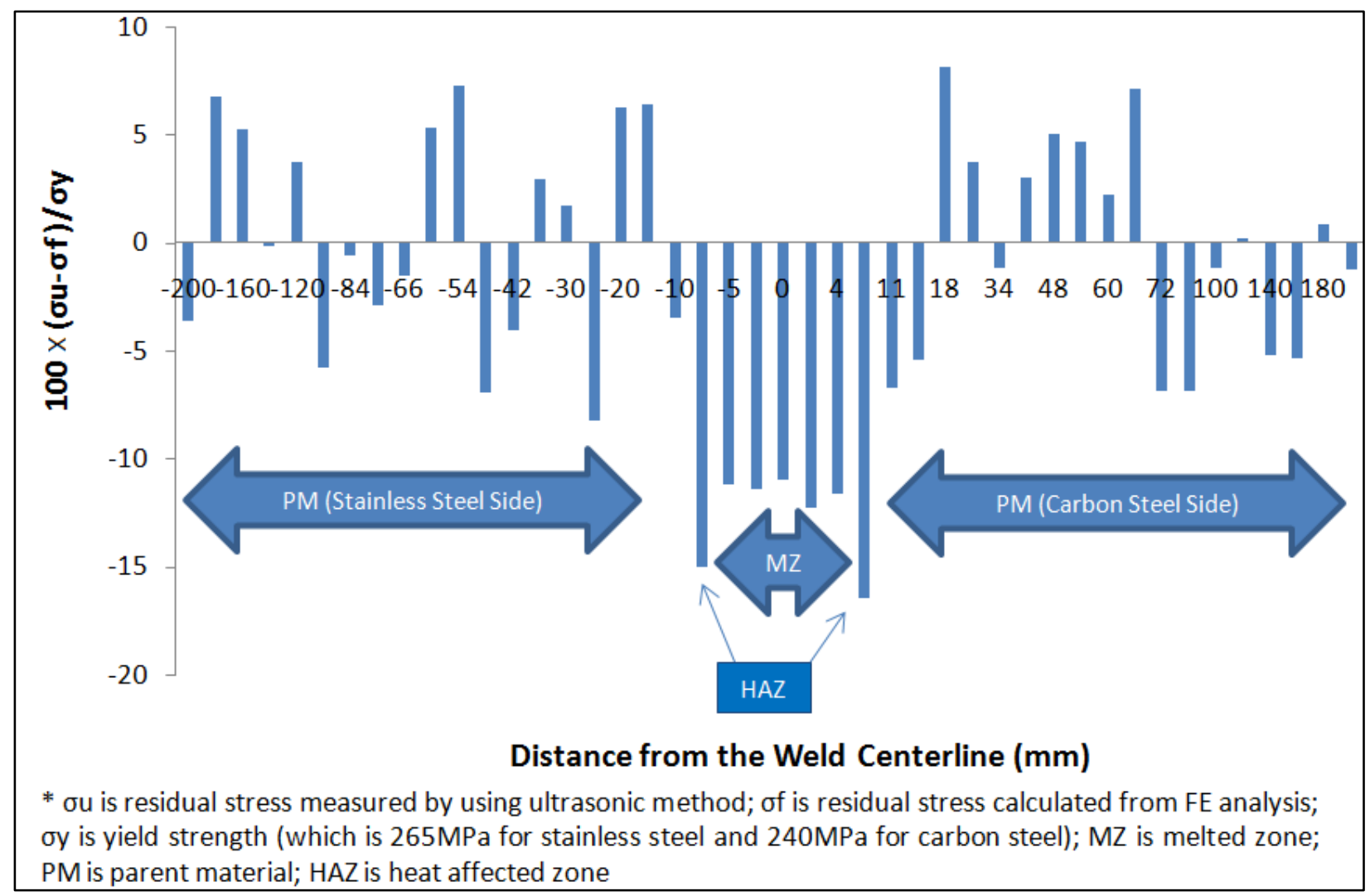

Fig. 15 Percentage difference between FE results and ultrasonic measurement related to the hoop stresses

The results presented in Fig. 14 show percentage difference according to the inspected zone (PM, HAZ or MZ) between FE and ultrasonic results related to the axial stress. There is a lot of dispersion in the PM results while it does not exceed than $\pm 10 \%$. The percentage results show more difference (13-17\%) in the MZ however, the maximum is observed in the HAZ (about $23 \%$ ). This high dispersion is also presented in Fig. 15 where the hoop stresses are considered. The maximum of percentage difference is $7 \%, 12 \%$ and $16 \%$ in the PM, MZ and HAZ respectively. The results show higher dispersion in the axial residual stresses in comparison with those obtained from the hoop stresses results because:

a. The axial wedge scans the pipe perpendicular to the weld line (Fig. 6). It means that the $L_{C R}$ wave propagated by this wedge, can sometimes pass from all three region of PM, HAZ and MZ simultaneously. Therefore, distinguishing between TOF influenced by which MZ or PM region is more difficult than similar situation related to the hoop measurement.

b. The acoustoelastic constant is measured in samples extracted parallel to the weld which can be used to calculate the hoop stresses. Using this acoustoelastic constant can lead to error in axial stress calculations.

Due to the above reasons, the percentage difference between FE and ultrasonic measurements of axial stresses is 3 percent (in the PM) and 7 percent (in the HAZ) more than those related to the hoop stresses. The mentioned reasons can lead to more difference in axial and hoop measurement but a practical limitation of hoop ultrasonic measurement has moderated the results. The surface deformations and ovality of the pipe influence on the hoop measurement results more than axial measurements. The reason is curved shape of the hoop wedge which can meet deformations of the pipe more than relatively flat bottom surface of the axial wedge.

There are also some practical difficulties in ultrasonic stress measurements of dissimilar joints. The velocity of ultrasonic wave is different in two sides of the weld which causes difference in the first critical angle. It is needed to construct two wedges with different angles to move from one side to another side of dissimilar joint. Creating two wedges with the same exact dimensions is practically impossible and could be an important reason for ultrasonic measurement error. Furthermore, the penetration depth of $L_{C R}$ wave is affected by the material and can be changed in dissimilar joints. Since the residual stresses are altered 
through the thickness, it is not possible to achieve a continuous distribution of residual stress with different depth measurement of stresses. Fortunately, these problems are not present in case of investigated stainless to carbon steel joint. The measured velocity of ultrasonic wave is approximately the same and do not considerably influence on the first critical angle. The penetration depth of the $L_{C R}$ wave is also the same for the investigated materials. Therefore, the same wedge is used here in ultrasonic measurement of two sides of the pipe. But, it is not recommended to use the ultrasonic stress measurement in dissimilar joint of materials with highly different mechanical and ultrasonic properties.

\section{5- CONCLUSIONS}

The main goal of this paper is investigating the nondestructive capability of $L_{C R}$ ultrasonic method in residual stress measurement of dissimilar welded pipes. Finite element model, hole-drilling and ultrasonic stress measurements methods are employed on two dissimilar welded pipes and plates with the same material, thickness and WPS. The acoustoelastic constant is measured on the plate while the pipe is kept intact to be measured in terms of ultrasonic wave TOF. According to the achieved results, it can be concluded that:

1) FE analysis has logically predicted the quality and quantity of the axial and hoop residual stresses of dissimilar pipe. Its validity is confirmed with hole-drilling measurements of the outer surface.

2) The FE results show higher axial and hoop residual stress in the stainless steel side of the pipe which is due to its higher yield stress in comparison with the carbon steel.

3) The acoustoelastic constant of the carbon steel is higher than stainless steel while the acoustoelastic constant of weld zone is the highest.

4) The measured acoustoelastic constant of dissimilar plate with the same specifications of the pipe, can be used in pipe stress measurement. However, the measurement error is raised in the weld zone because of inherent difference between pipe and plate welding.

5) Since the $L_{C R}$ method measures the average of the stresses, the average of FE results in $0-2 \mathrm{~mm}$ under the surface is compared with the ultrasonic measurements.

6) The FE and ultrasonic results demonstrate acceptable agreement according to the axial and hoop residual stresses of the pipe. The best agreement is observed in the parent material while the weld zone has the higher disagreement. The maximum disagreement is measured in the HAZ because its acoustoelastic constant is not measured.

7) The welding residual stresses of a dissimilar pipe are evaluated by ultrasonic $L_{C R}$ waves while the pipe is intact and the measurement is completely nondestructive.

8) It is not recommended to use the ultrasonic stress measurement in dissimilar joint of materials with highly different mechanical and ultrasonic properties.

[1]

\section{6- REFERENCES}

[2] Josepha A, Raib Sanjai K, Jayakumara T, Muruganc N (2005) Evaluation of residual stresses in dissimilar weld joints. International Journal of Pressure Vessels and Piping 82:700-705.

[3] Rossini NS, Dassisti M, Benyounis KY, Olabi AG (2012) Methods of measuring residual stresses in components. J Materials \& Design 35:572-588.

[4] Egle DM, Bray DE (1976) Measurement of Acoustoelastic and Third-Order Elastic Constants for Rail Steel. J Acoust Soc Am 60:741-744.

[5] Basatskaya LV, Ermolov IN (1981) Theoretical analysis of ultrasonic longitudinal undersurface waves in solid medium. Sov J Nondestruct Test 16: 524-530.

[6] Langenberg KJ, Fellenger P, Marklein R (1990) On the nature of the so-called subsurface longitudinal wave and/or the surface longitudinal 'creeping' wave. Res Nondestruct Eval 2: 59-81.

[7] Chaki S, Ke W, Demouveau H (2013) Numerical and experimental analysis of the critically refracted longitudinal beam. Ultrasonics 53: 65-69.

[8] Bray DE, Junghans PG (1995) Applications of the $L_{C R}$ Ultrasonic Technique for Evaluation of Post-Weld Heat Treatment in Steel Plates. NDT\&E International 28: 235-242.

[9] Leon-Salamanca T, Bray DF (1995) Residual Stress Measurements in Steel Plates and Welds Using Critically Refracted $\left(L_{C R}\right)$ Waves. Research in Nondestructive Evaluation 7:169-184.

[10] Tanala E, Bourse G, Fremiot M, De Belleval JF (1995) Determination of near surface residual stresses on welded joints using ultrasonic method. NDT\&E International 28:83-88. 
[11] Belahcene F, Lu J (2002) Determination of residual stress using critically refracted longitudinal waves and immersion mode. The Journal of Strain Analysis for Engineering Design 37: 13-19.

[12] Walaszek H, Hoblos J, Bouteille P, Bourse G, Robin C (2006) Ultrasonic Stress Measurement: Application to Welded Joints. ECNDT Tu.4.8.3.

[13] Lu H, Liu XS, Yang JG, Zhang SP, Fang HY (2008) Ultrasonic stress evaluation on welded plates with $L_{C R}$ wave. Science and Technology of Welding and Joining 13:70-74.

[14] Palanichamy P, Vasudevan M, Jayakumar T (2009) Measurement of residual stresses in austenitic stainless steel weld joints using ultrasonic technique. Science and Technology of Welding and Joining 14:166-171.

[15] Qozam H, Chaki S, Bourse G, Robin C, Walaszek H (2010) Microstructure Effect on the Lcr Elastic Wave for Welding Residual Stress Measurement. Experimental Mechanics 50: 179-185.

[16] Goldak J, Bibby M (1988) Computational Thermal Analysis of Welds. Modeling of Casting and Welding Processes 4:153-166.

[17] Yan D, Wu A, Silvanus J, Shi Q (2011) Predicting residual distortion of aluminum alloy stiffened sheet after friction stir welding by numerical simulation. J Materials \& Design 32:2284-2291.

[18] Sattari-Far I, Javadi Y (2008) Influence of welding sequence on welding distortions in pipes. Int J of Pressure Vessels and Piping 85:265-274.

[19] Goldak J, Akhlaghi M (2005) Computational Welding Mechanics. Springer.

[20] Lindgren LE (2001) Finite element modelling and simulation of welding part 2: improved material modeling. J Thermal Stress 24:195-231.

[21] Lindgren LE, Hedblom R (2001) Modelling of addition of filler material in large deformation analysis of multipass welding. Commun Numer Methods Eng 17:647-57.

[22] Chang P, Teng T (2004) Numerical and experimental investigations on the residual stresses of the butt-welded joints. Computational Materials Science 29:511-522.

[23] A. Schaeffler (1949) Constitution diagram for stainless steel weld metal. Metal Progress 1:680-680.

[24] Lindgren LE (2001) Finite Element Modelling and Simulation of Welding Part 1: Increased complexity. J Thermal Stress 24:141-92.

[25] Deng D, Murakawa H (2006) Numerical simulation of temperature field and residual stress in multi-pass welds in stainless steel pipe and comparison with experimental measurements. Computational Materials Science 37:269277.

[26] Auteliano A. Santos, Marcilio Haddad Andrino, Don E. Bray, Roseana E. Trevisan (2008) Evaluation of Stresses Generated by Welding in API 5L X65 Steel using Acoustoelasticity. Materials Evaluation 66: 858-864. 